\title{
Climate change shifts the spawning ground northward and extends the spawning period of chub mackerel in the western North Pacific
}

\author{
Yuki Kanamori ${ }^{1, *}$, Akinori Takasuka ${ }^{1,2}$, Shota Nishijima ${ }^{1}$, Hiroshi Okamura ${ }^{1}$ \\ ${ }^{1}$ National Research Institute of Fisheries Science, Japan Fisheries Research and Education Agency, 2-12-4 Fukuura, \\ Kanazawa, Yokohama, Kanagawa 236-8648, Japan \\ ${ }^{2}$ Present address: Graduate School of Agricultural and Life Sciences, The University of Tokyo, 1-1-1 Yayoi, Bunkyo, \\ Tokyo 113-8657, Japan
}

\begin{abstract}
Despite extensive studies of phenological shifts associated with climate change, a few unresolved issues remain. In particular, little is known about the phenological shifts of marine organisms, and simultaneous evaluations of phenological and distributional shifts in reproduction are needed. Chub mackerel Scomber japonicus in the western North Pacific is a small pelagic fish species with its main spawning ground around the Izu Islands. Since its spawning patterns are affected by the sea surface temperature (SST), changes in the spawning time and spawning ground are expected if the SST has increased around the Izu Islands. Here, to elucidate phenological and distributional shifts in reproduction associated with climate change and the underlying causes, we first examined the long-term changes in spawning patterns and spawning ground using a geostatistical model with $40 \mathrm{yr}$ time series data for spawning eggs of chub mackerel in the western North Pacific. We then tested the prediction that increasing SST impacts the timing and distribution of chub mackerel reproduction. We found that the spawning period was extended owing to a delay in the end of spawning. The geographic location of the spawning ground moved northward after the 2000s, and this was probably related to the change in SST. In addition, SST in the spawning ground after the 2000s was not significantly different from the SST in the previous spawning ground. Therefore, the environmental change associated with climate change likely influences phenological and distributional shifts in reproduction simultaneously and underlines the importance of focusing on spatio-temporal changes in reproduction.
\end{abstract}

KEY WORDS: Distributional shifts $\cdot$ Phenological shifts $\cdot$ Spatio-temporal model $\cdot$ Small pelagic fish

\section{INTRODUCTION}

Climate change has significant impacts on organisms in terrestrial and marine habitats (e.g. Walther et al. 2002, Doney et al. 2012). Since temperature is a major abiotic factor that affects phenology (i.e. the seasonal timing of life-history events, such as reproduction and migration), global warming is increasingly disrupting natural phenological patterns (Cleland et al. 2007, Asch 2015). Advances in the seasonal timing of reproduction are some of the most frequently reported phenomena in studies of the impacts of cli-

*Corresponding author: kana.yuki@fra.affrc.go.jp mate change (e.g. Parmesan \& Yohe 2003, Root et al. 2003, Asch 2015). A few challenging issues related to phenological shifts, however, remain unresolved. The first issue is that little is known about phenological shifts in marine organisms. Phenological patterns of terrestrial organisms, such as the migration of birds and flowering of plants, are easy to record because these species are common and easily identifiable (Walther et al. 2002). By contrast, the phenology of marine organisms is difficult to monitor (Sims et al. 2004, Greve et al. 2005, Hovel et al. 2017), owing to the cost and time needed to conduct surveys (Winder

(C) The authors 2019. Open Access under Creative Commons by Attribution Licence. Use, distribution and reproduction are unrestricted. Authors and original publication must be credited. 


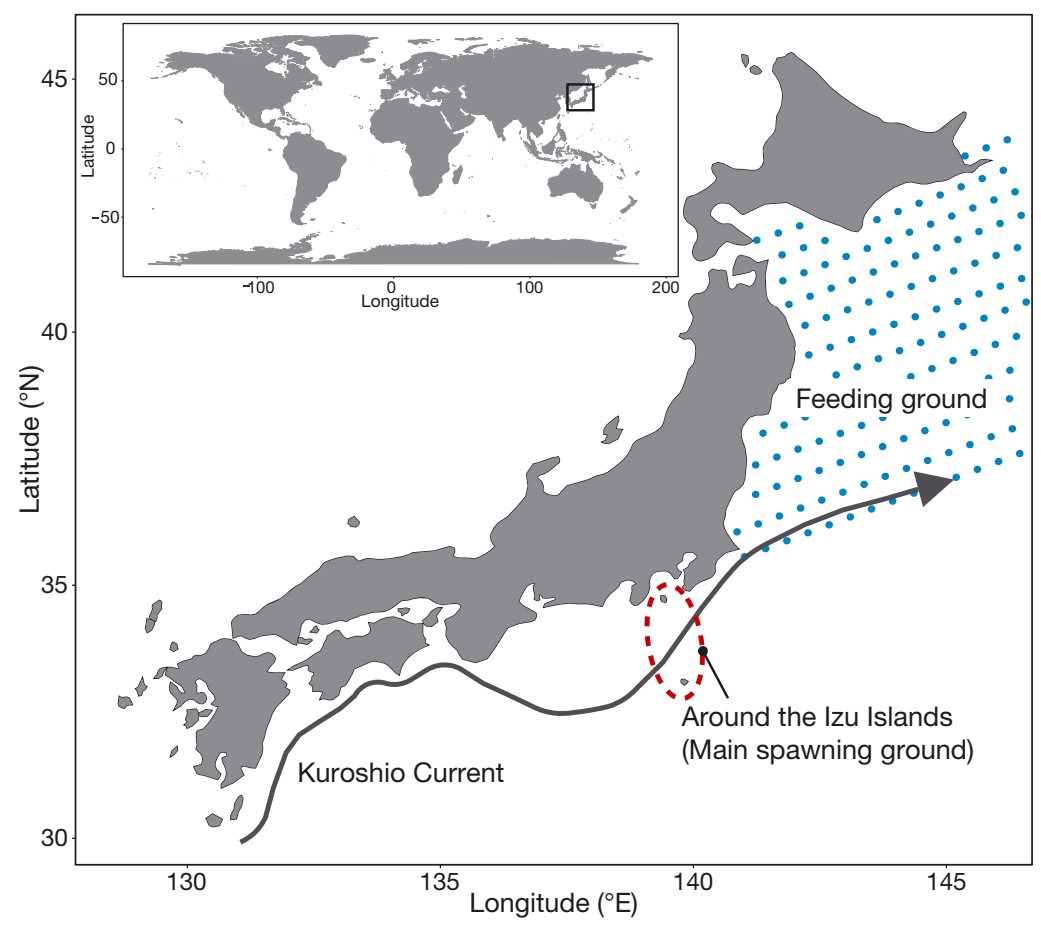

Fig. 1. Study area. Chub mackerel Scomber japonicus in the western North Pacific mainly spawn around the Izu Islands, Japan. Adults and their offspring are then transported to the feeding ground by the Kuroshio Current change (Beaugrand \& Kirby 2018). Second, they are an important food resource (i.e. forage fish) for numerous top predators, such as large pelagic fish, demersal fish, marine birds, and marine mammals. Phenological shifts associated with climate change can have a large impact on whole marine ecosystems through trophic cascades (Edwards \& Richardson 2004). Third, they are commercially important, accounting for about $60 \%$ of the total catch of major marine fish (FAO 2018); this suggests that phenological shifts in this species can potentially alter ecosystem services.

Chub mackerel Scomber japonicus are small pelagic fish distributed in the western North Pacific, from Kyushu Island to Hokkaido, Japan (ca. 130$145^{\circ}$ E, Fig. 1; Watanabe \& Yatsu 2006). They spawn mainly around the Izu Islands from spring to summer (e.g. Watanabe 1970, Watanabe et al. 1999, Watanabe \& Yatsu 2006), after which the adults and their offspring are trans-

\& Schindler 2004, Thackeray et al. 2008) and the difficulty in species identification based on eggs (Takasuka et al. 2008a) and larvae (Asch 2015), whose morphological characteristics are likely to overlap among species (Ko et al. 2013). The second issue is the necessity to simultaneously evaluate phenological and distributional shifts in reproduction. Because climate change also affects species distributions (e.g. Sims et al. 2001, 2004, Cherry et al. 2013), phenology (i.e. seasonal timing) and reproductive habitats could covary.

To investigate phenological shifts in marine organisms, it is advantageous to focus on small pelagic fishes, such as sardine, anchovy, herring, and mackerel, which are commonly defined as shoaling epipelagic fish with high mobility in coastal areas and an adult body length of about 10-30 cm (Fréon et al. 2005). They have a greater tendency to respond to changes in temperature seasonality than other species (Henderson et al. 2017), for several reasons. First, they live in the surface layer of the ocean, usually at depths of 0-200 m (Fréon et al. 2005). In general, physical environments in marine systems (e.g. water temperature and light intensity) fluctuate more in the upper layer; accordingly, organisms that live in the surface layer are more likely to experience the environmental changes associated with climate ported to the feeding ground by the Kuroshio Current (e.g. Watanabe 1970, Watanabe \& Nishida 2002). They exhibit a stenothermal spawning pattern with a steep mode of ca. $18^{\circ} \mathrm{C}$ (Takasuka et al. 2008a), implying a high sensitivity of this species to changes in sea temperature.

If the sea surface temperature (SST) has been increasing due to climate change around the Izu Islands, 1 of 4 scenarios may be expected: (1) the spawning time of chub mackerel may be advancing in response to the increasing SST, as observed for most terrestrial species; (2) the spawning ground may be changing without a change in the spawning time; (3) an advancing spawning time and changing spawning ground are simultaneously occurring; or (4) neither an advancing spawning time nor a changing spawning ground is occurring. Here, to elucidate the changes in phenological and distributional shifts in reproduction associated with climate change as well as the causes of these changes, we first examined the long-term changes in spawning patterns and spawning ground using 4-decade time series data for spawning eggs of chub mackerel in the western North Pacific. We then tested the prediction that an increasing SST impacts changes in the timing and distribution of chub mackerel reproduction, as revealed by the first analysis. 


\section{METHODS}

\subsection{Data sets}

As egg density data have been used previously to analyze spawning habitats of small pelagic fish species (Oozeki et al. 2007, Takasuka et al. 2008a,b), monthly egg density data with $30^{\prime}$ latitude $\times 30^{\prime}$ longitude horizontal square resolution in the areas from $130-145^{\circ} \mathrm{E}$ and $30-43^{\circ} \mathrm{N}$ were used. The egg density data set was derived from monthly egg surveys off the Pacific coast of Japan from March to July of 1978-2017 (Takasuka et al. 2008a, 2019). The aim of the surveys was to monitor egg abundance of major small pelagic fish species, including chub mackerel, in the western North Pacific. The survey area covered the majority of the major spawning ground of small pelagic fish for $40 \mathrm{yr}$. Some sampling locations were fixed, while others varied for various reasons, such as environmental conditions. Therefore, the survey design changed slightly each year and extended northward over time (Fig. S1 in the Supplement at www.int-res. com/articles/suppl/m624p155_supp.pdf). The sampling effort was approximately consistent year-round, although it tended to be more intensive during early spring; effort was highest in February and decreased gradually thereafter (Takasuka et al. 2008b).

Monthly surveys were conducted by 18 prefectural experimental stations or fisheries research institutes and 2 national research institutes of the Japan Fisheries Research and Education Agency following the same procedure. In the surveys, plankton nets were towed vertically from a depth of $150 \mathrm{~m}$ to the surface or from approximately $10 \mathrm{~m}$ less than the depth in areas shallower than $150 \mathrm{~m}$. This range of depths covered the distributions of eggs of small pelagic fish. The surveys used 4 kinds of plankton nets, with mouth ring diameters of 0.45 or $0.60 \mathrm{~m}$ and mesh sizes of 0.330 or $0.335 \mathrm{~mm}$ (Takasuka et al. 2017). After the surveys, the number of eggs per unit area in the water column (number $\mathrm{m}^{-2}$ ) for each sampling tow was calculated by flow-meter revolutions, flowmeter revolutions per meter tow in the calibration, wire length $(\mathrm{m})$, opening mouth area of the net $\left(\mathrm{m}^{2}\right)$, and wire angle. The number of eggs was then averaged arithmetically with $30^{\prime}$ latitude $\times 30^{\prime}$ longitude horizontal square resolution. More detailed descriptions of the surveys and data set are provided in previous studies of the reproductive biology of small pelagic fish species (e.g. Takasuka et al. 2008a,b, 2017, 2019).
The egg density data set included 2 species in the genus Scomber: chub mackerel S. japonicus and spotted mackerel $S$. australasicus. Species identification based on egg diameter was not performed before 2006. We assumed that the total egg density of the 2 species reflected the egg density of chub mackerel for the overall study period because the spawning stock biomass was much higher for chub mackerel than for spotted mackerel after 2006 (Yukami et al. 2017), although the spawning stock biomass of spotted mackerel was much higher from 2006 to 2017 than from 1995 to 2005 (Yukami et al. 2017). Furthermore, the egg density was much higher for chub mackerel than for spotted mackerel; chub mackerel accounted for 75 to $96 \%$ of the total egg density of the 2 species (A. Takasuka et al. pers. obs.). To validate our assumption, we repeated the analyses using subsets of data that included only chub mackerel as well as both chub mackerel and spotted mackerel after 2006 and confirmed that there were no differences in the essential results among data subsets (Figs. S2-S5).

The mean global daily SST since 1982 with 25' latitude $\times 25^{\prime}$ longitude horizontal square resolution in the area archived as MGDSST by the Japan Meteorological Agency (https://ds.data.jma.go.jp/gmd/goos/ data/database.html) was used. In this data set, the monthly mean SST exhibited significant positive trends in some locations from May to July and increased northward (Fig. S6, Table S1).

\subsection{Data analyses}

\subsubsection{Estimation of spatio-temporal variation in egg density}

To estimate spatio-temporal variation in monthly egg density by considering sampling effects, such as spatio-temporal changes in survey design (Fig. S1), we used the multivariate vector autoregressive spatiotemporal (VAST) model (Thorson \& Barnett 2017), which accounts for spatio-temporal changes in survey design, survey effort, and observation rates and can accurately estimate relative local densities at high resolution by standardizing sampling designs (Thorson \& Barnett 2017, Thorson 2019). The VAST model can therefore partially overcome the difficulty in the long-term monitoring of marine organisms. While previous studies have mainly used this model to estimate spatio-temporal variation in the abundance of multiple species (e.g. Thorson \& Barnett 2017), in this study, it was used to estimate spatio- 
yearly variation in egg density over multiple seasons, namely, from March to July. The model includes 2 potential components because it is designed to support delta-models: (1) the encounter probability $p_{i}$ for each sample $i$ and (2) the expected egg density $d_{i}$ for each sample $i$ when spawning occurs (i.e. egg density is not 0 ). $p_{i}$ and $d_{i}$ are, respectively, approximated using a logit-linked linear predictor and a log-linked linear predictor as follows (Thorson \& Barnett 2017):

$$
\begin{aligned}
\operatorname{logit} p_{i} & =\beta_{p}\left(t_{i}, C_{i}\right)+\omega_{p}\left(s_{i}, C_{i}\right)+\varepsilon_{p}\left(s_{i}, C_{i}, t_{i}\right) \\
\log d_{i} & =\beta_{d}\left(t_{i}, C_{i}\right)+\omega_{d}\left(s_{i}, C_{i}\right)+\varepsilon_{d}\left(s_{i}, c_{i}, t_{i}\right)
\end{aligned}
$$

where $\beta\left(t_{i}, c_{i}\right)$ is the intercept for year $t$ and month $C_{1}$ and $\omega\left(S_{i}, C_{i}\right)$ and $\varepsilon\left(s_{i}, C_{i}, t_{i}\right)$ are spatial and spatiotemporal random effects for year $t$, month $c$, and location $s$.

SST was not used as a density covariate in the model for 3 reasons. First, our focus was not on the effect of SST on local egg density but on the effects of long-term changes in SST (increasing mean and variability) associated with climate change on phenological and distributional shifts. Second, the VAST model assumes a linear effect of SST on local egg density, although this has not been established. Finally, using the VAST model, it is difficult to detect effects of SST on spatio-temporal factors, such as the center of gravity (COG) of the spatial distribution of species. Previous analyses have shown that temporal changes in COG are largely unexplained by temperature in species whose distributional shifts are caused by temperature (Thorson et al. 2017).

The 3-dimensional Gaussian process was modeled for spatio-temporal variation $\varepsilon_{p}\left(s_{i}, C_{i}, t_{i}\right)$ (Thorson \& Barnett 2017):

$$
\operatorname{vec}\left[\mathbf{E}_{p}(t)\right] \sim \operatorname{MVN}\left(0, \mathbf{R}_{p} \otimes \mathbf{V}_{\varepsilon p}\right)
$$

where $\mathbf{E}_{p}(t)$ is the $n_{\text {location }} \times n_{\text {month }}$ matrix whose elements are $\varepsilon_{p}\left(s_{i}, c_{i}, t_{i}\right)$ in a given year $t$, and $\operatorname{vec}\left[\mathbf{E}_{p}(t)\right]$ is a vector whose elements are $\mathbf{E}_{p}(t) . \mathbf{R}_{p}$ is the $n_{\text {location }} \times$ $n_{\text {location }}$ correlation matrix representing spatial correlation in $\varepsilon_{p}\left(S_{i}, C_{i}, t_{i}\right) . \mathbf{V}_{\varepsilon p}$ is the $n_{\text {month }} \times n_{\text {month }}$ covariance matrix representing correlation in $\varepsilon_{p}\left(s_{i}, c_{i}, t_{i}\right)$ in year among months. $\otimes$ is the Kronecker product, and $\mathbf{R}_{p} \otimes$ $\mathbf{V}_{\varepsilon p}$ is the covariance matrix between any month $C$ and location $s$ in year $t$. $\mathbf{E}_{d}(t)$ follows an identical distribution, but with $\mathbf{R}_{p}$ and $\mathbf{V}_{\varepsilon p}$ in place of $\mathbf{R}_{d}$ and $\mathbf{V}_{\varepsilon p}$.

For computational reasons, $\varepsilon_{p}\left(S_{i}, C_{i}, t_{i}\right)$ was approximated as being piecewise constant at a fine spatial scale. We used a $k$-means algorithm to identify 150 locations (termed 'knots') to minimize the total distance between the location of sampling data (Thorson et al. 2015) using R-INLA software (Lindgren 2012). The number of knots was increased to the greatest extent possible, and similar results were obtained for low knots (=90; Akaike's information criterion, $\mathrm{AIC}=42324.33)$ and high knots $(=150$; $\mathrm{AIC}=41820.11$ ).

Parameters in the VAST model were estimated using the VAST package (Thorson et al. 2015, 2016) in R 3.5.0 (R Development Core Team 2018). Biascorrection for random effects (Thorson \& Kristensen 2016) was applied when estimating the derived parameters. Model diagnostics plots are provided in the Supplement (Figs. S7-S14). The index of abundance in year $t$ and month $c$ at location $s, \hat{d}(s, C, t)$ and the index of abundance in year $t$ and month $c, \hat{D}(c, t)$, were estimated using the predicted values for random effects as follows (Thorson et al. 2017):

$$
\begin{aligned}
& \hat{d}(s, C, t)= \operatorname{logit}{ }^{-1}\left[\beta_{p}(t, c)+\omega_{p}(s, C)+\varepsilon_{p}(s, C, t)\right] \\
& \times \exp \left[\beta_{d}(t, C)+\omega_{d}(s, C)+\varepsilon_{d}(s, C, t)\right] \\
& \hat{D}(C, t)=\sum_{s} a(s) \times \hat{d}(s, c, t)
\end{aligned}
$$

where $a(s)$ is the area of location $s$. Hereafter, $\hat{d}(s, c, t)$ and $\hat{D}(c, t)$ are referred to as the 'index of abundance in each location' and 'index of abundance,' respectively. The results obtained using default settings in the VAST package are provided in the Supplement (Figs. S15-S20).

\subsubsection{Spawning pattern and spawning ground}

To examine the long-term changes in spawning patterns, the start, end, peak, and period of spawning in each year were estimated using the index of abundance $\hat{D}(c, t)$. Seasonal spawning patterns for the index of abundance $\hat{D}(c, t)$ in each year are shown in Fig. S21. The start and end month of spawning in each year were defined as the $25^{\text {th }}$ and $75^{\text {th }}$ percentiles in the seasonal spawning patterns for the index of abundance in each year, respectively (Fig. S21). The spawning period in each year was defined as the difference between the start month and end month of spawning in each year. The spawning peak in each year was defined as the mode of the seasonal spawning patterns for the index of abundance in each year (Fig. S21). The long-term trends in spawning properties (start, end, peak, and period of spawning) were examined by linear regression analysis using R 3.5.0 (R Development Core Team 2018).

To verify the sensitivity of our results to the measurements of spawning patterns, the spawning peaks in year $t, T(t)$, were estimated using the month coordinate of the COG of the area below graphs of 
monthly means (Colebrook \& Robinson 1965, Colebrook 1979, Edwards \& Richardson 2004):

$$
\hat{T}(t)=\frac{\sum_{c} c \times \hat{D}(c, t)}{\sum_{c} \hat{D}(c, t)}
$$

In addition, the start and end months of spawning in each year were estimated as the $10^{\text {th }}$ and $90^{\text {th }}$ percentiles in the histogram of monthly changes in the index of abundance in each year, respectively. The spawning periods in each year were similarly estimated as the differences between the start and end months of spawning in each year. The long-term trends in spawning properties (start, end, peak, and period of spawning) were examined by linear regression analysis, and a lack of differences in results was confirmed.

To examine long-term changes in the spawning ground, we estimated inter-annual patterns of the geographic location of the COG in each month using the index of abundance for each location $\hat{d}(s, c, t)$ (Thorson et al. 2017). Following Thorson et al. (2017), the latitudinal and longitudinal COG in year $t$ and month $c, \mathrm{COG}_{\mathrm{Lat} .}(c, t)$ and $\mathrm{COG}_{\mathrm{Lon} .}(c, t)$ were estimated as:

$$
\begin{gathered}
\overline{\mathrm{COG}_{\text {Lat. }}(c, t)}=\frac{\sum_{s=1}^{n_{s}} \hat{d}(s, C, t) \times \text { Latitude }(s)}{\sum_{s=1}^{n_{s}} \hat{d}(s, c, t)} \\
\overline{\mathrm{COG}_{\text {Lon. } .}(c, t)}=\frac{\sum_{s=1}^{n_{s}} \hat{d}(s, c, t) \times \text { Longitude }(s)}{\sum_{s=1}^{n_{s}} \hat{d}(s, c, t)}
\end{gathered}
$$

where Latitude(s) and Longitude(s) are the latitude and longitude of the location $s$. The default result from the VAST package is provided in Fig. S22.

\subsubsection{Effect of SST on distributional shift}

To understand mechanisms underlying phenological and distributional shifts revealed by the above analyses, we investigated the effect of the SST on the long-term change in spawning ground (i.e. COG) using 2 methods: (1) by determining whether longterm changes in COG were affected by increasing SST and (2) by determining whether the SST in the present COG is similar to the SST in previous COGs. In the first method, if chub mackerel spawns around a habitat with a suitable temperature, the SST at the COG cannot change because the COG of chub mackerel changes inter-annually in response to the
SST. To test this, we randomized the year of COG in each month and calculated yearly trends in SST at the COG in each month by linear regression analysis. After replicating the trials 1000 times, we estimated the probabilities that the yearly trend in SST at the COG (i.e. the slope of SST at the COG against year) obtained from observations was lower than the yearly trend in SST of the COG obtained from randomization.

In the second method, if chub mackerel spawns around habitats with a suitable temperature, the present COG is situated in a location with a more similar SST to those of previous spawning grounds, such as around the Izu Islands, a major spawning ground of chub mackerel (Fig. 1). To examine this, we first set the 12 locations by $0.5^{\circ}$ longitude (Fig. S6a), reflecting the results for long-term changes in the COG. We chose location 4 (Fig. S6a) around the Izu Islands as the previous spawning ground. We then calculated the pairwise dissimilarity between the present SST for each location (i.e. locations 1 to 12 in Fig. S6) and the previous SST around the Izu Islands (i.e. location 4 in Fig. S6a). Here, we defined previous as 'pre-2000' and present as 'post-2000' because the long-term changes in COG in each month shifted substantially around 2000. The pre-2000 SST and the post-2000 SST were compared by the KullbackLeibler divergence (Kullback \& Leibler 1951, Burnham \& Anderson 2001; hereafter referred to as the 'KL distance'). Since climate change generally increases both the mean and variability of temperatures, the KL distance, which measures the dissimilarity between 2 probability distributions, was used to compare previous and present SSTs. The equation for the KL distance is as follows:

$$
\text { KL distance }=\int_{-\infty}^{\infty} P\left(x \mid \mu, \sigma^{2}\right)\left(\log \frac{P\left(x \mid \mu, \sigma^{2}\right)}{Q\left(x \mid \mu, \sigma^{2}\right)}\right) \mathrm{d} x
$$

where $P\left(x \mid \mu, \sigma^{2}\right)$ is the density function of normal distributions of the previous SST around the Izu Islands (i.e. location 4 in Fig. S6a), and $Q\left(x \mid \mu, \sigma^{2}\right)$ is the density function of normal distributions of the present SST of each location, where $\mu$ is the mean SST and $\sigma^{2}$ is the variance. To examine statistical significance, a permutation test was conducted with the null hypothesis that pre-2000 SSTs in an area had the same probability distribution as post-2000 SSTs around the Izu Islands (location 4). SSTs were randomly resampled from the combined data sets pre-2000 and post2000 without replacement, and then the KL distance was calculated to obtain the null distribution. We replicated the procedure 1000 times and computed the probability that the observed KL distance is 


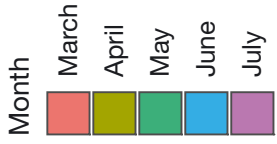

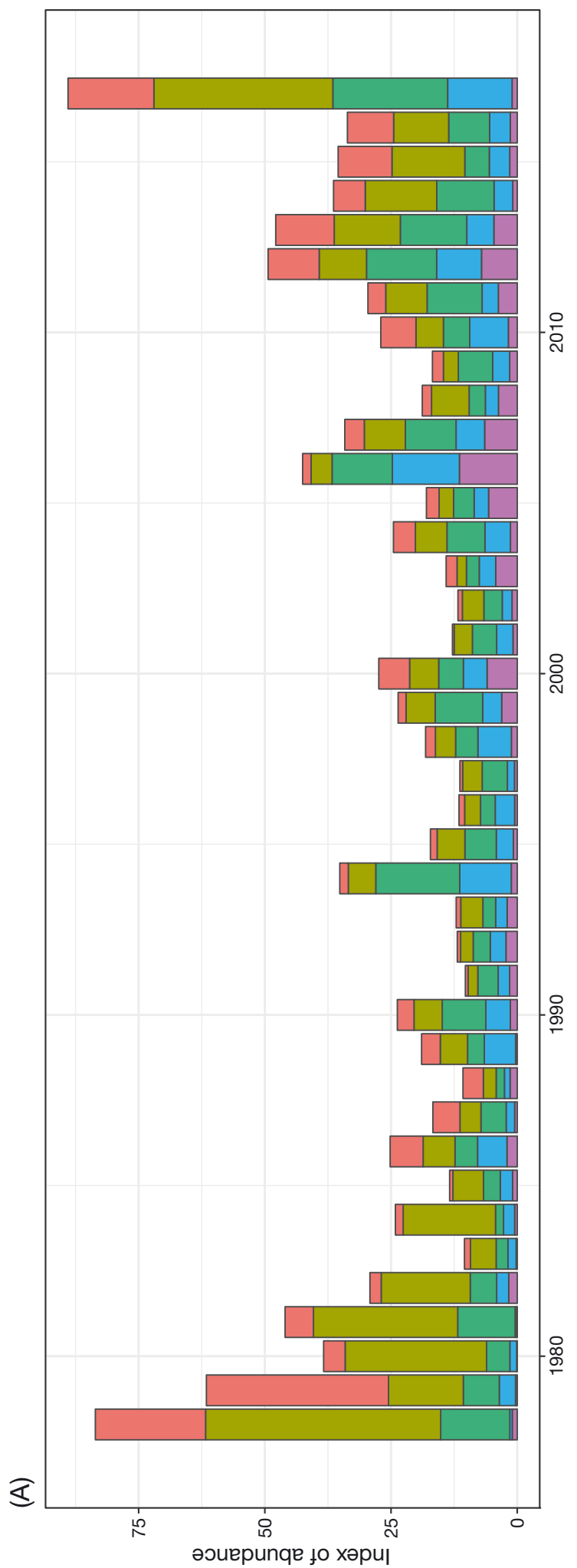

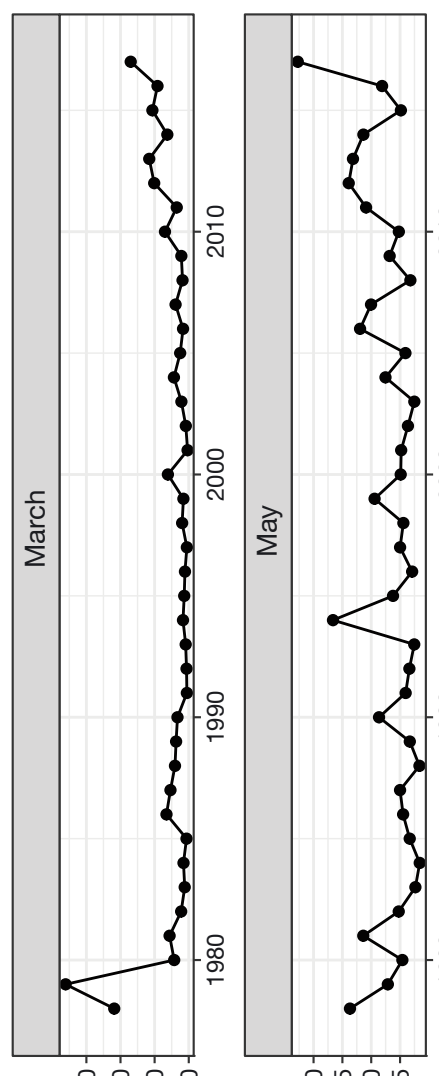

온든으 나

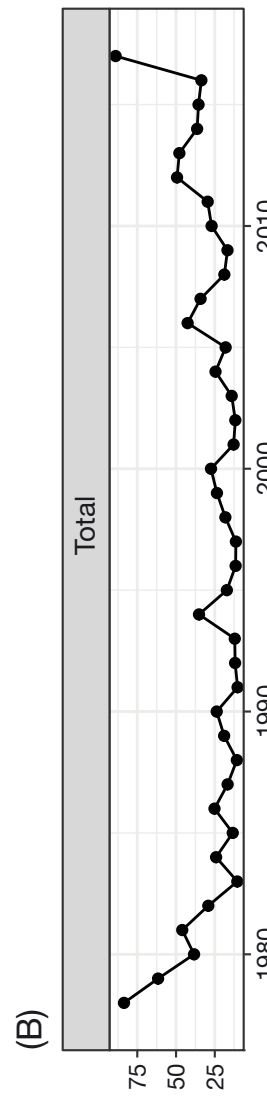

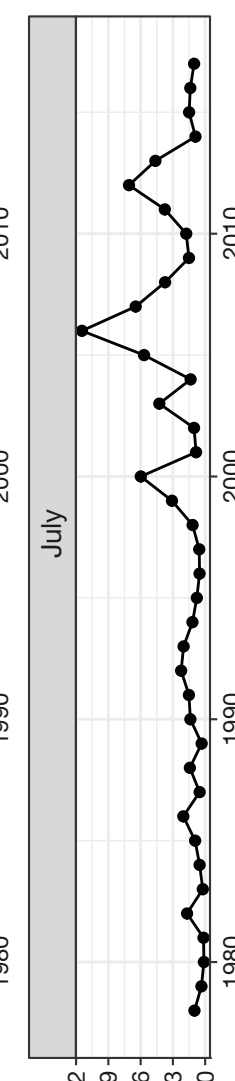

동

ช

ర్ల

응 코

4

de

द्व 0

8 पै

.

范

$\mathbb{4}$

in

2

요월

\} - 牙

$\left\{\begin{array}{l}z \\ 0 \\ 0 \\ 0\end{array}\right.$

永定

웡

$\Xi$.

굴

+ 묭

चี
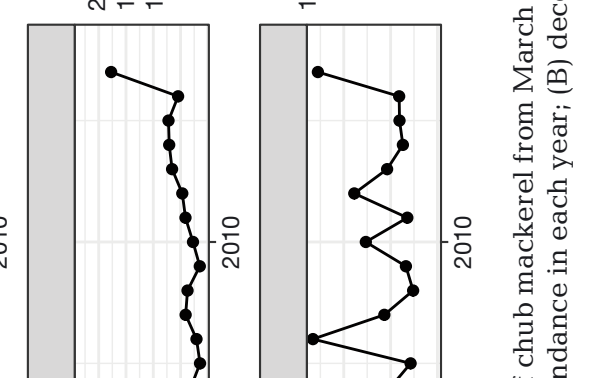

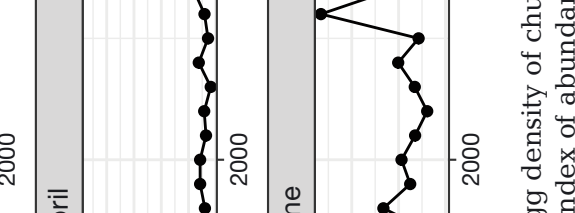

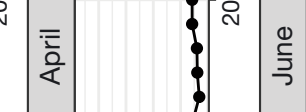

$<$

1 ब

10

\}

요의
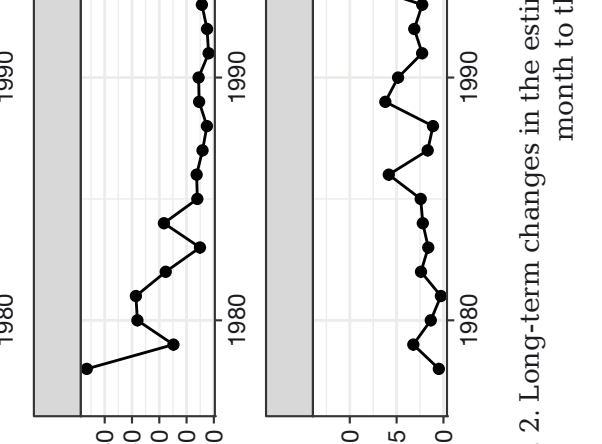
әоuepunqe łо хәрu|

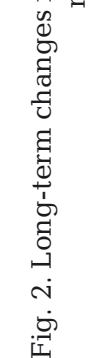


larger than the resampled KL distances. The probability was calculated for each location to infer where areas of reproduction with suitable SSTs moved in association with climate change. To confirm the sensitivity of our results to the assumption of previous spawning grounds, we also chose location 5 around the Izu Islands, calculated the pairwise similarity using the KL distance, and determined the statistical significance.

\section{RESULTS}

\subsection{Spawning pattern and spawning ground}

The index of abundance $\hat{D}(c, t)$ and sum of the index of abundance in each year (i.e. total index of abundance) fluctuated inter-annually (Fig. 2). The ratios of the index of abundance in April and May (Fig. 2A) to the total index of abundance in each year were frequently high over the $40 \mathrm{yr}$ period, whereas the ratios of the index of abundance in the other months to the total index of abundance in each year varied among years. The total index of abundance in each year decreased until around 2000 and increased thereafter.

Spawning patterns have gradually changed over $40 \mathrm{yr}$ (Fig. 3). The start of spawning did not change significantly $(y=0.004 x-3.43, p=0.61)$, whereas the end of spawning was significantly delayed $(y=$ $0.024 x-42.4, p<0.05)$. Reflecting the delay in the end of spawning, the period of spawning increased significantly $(y=0.020 x-38.0, p<0.05)$. The peak of spawning was also significantly delayed over time $(y=0.030 x-55.2, p<0.05)$. There were no differences in the trends when other measures of spawn-
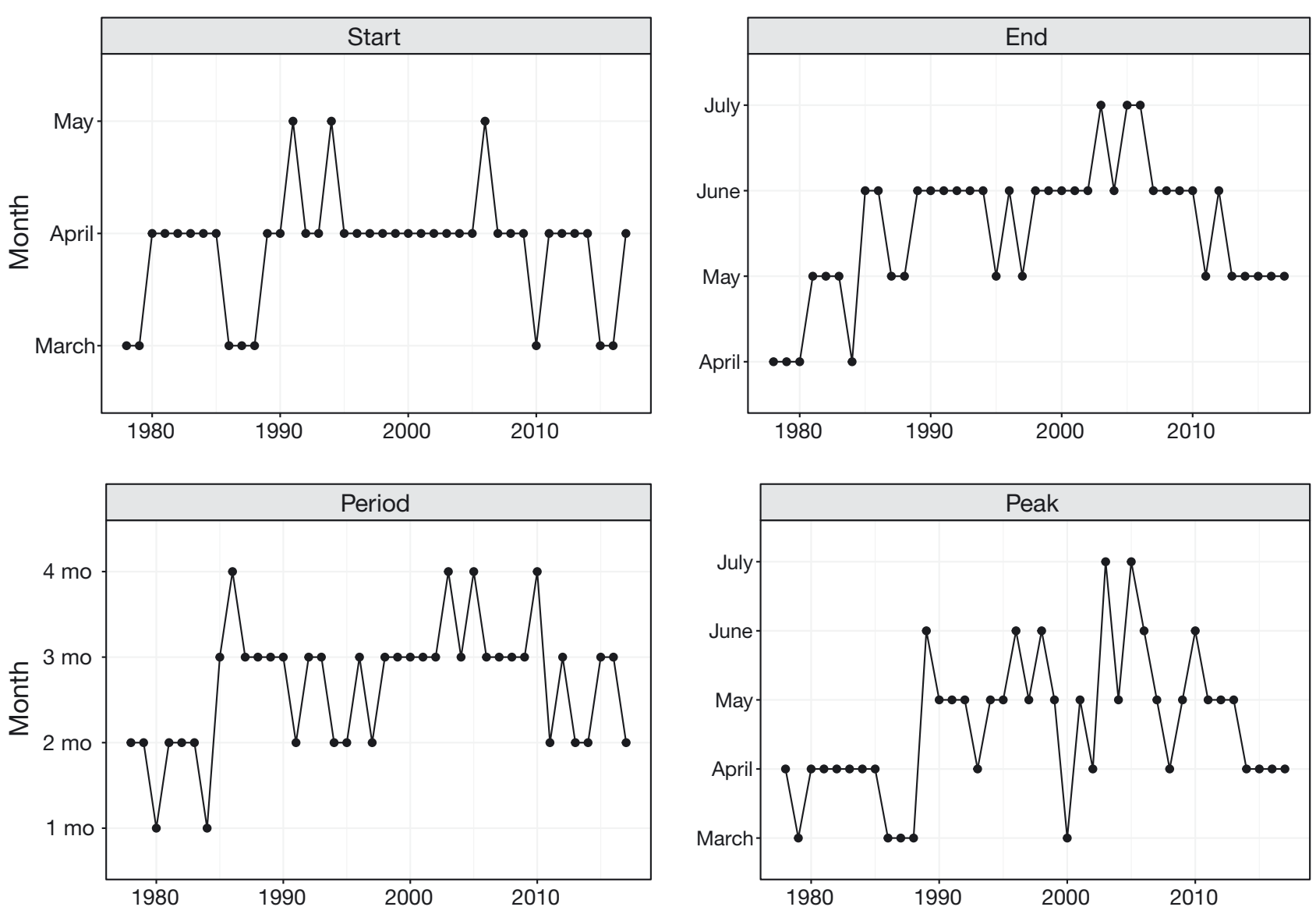

Fig. 3. Long-term changes in spawning patterns (start, end, period, and peak of spawning) of chub mackerel with linear regression lines. The start and end months of spawning were defined as the $25^{\text {th }}$ and $75^{\text {th }}$ percentiles in the histogram of monthly changes in the index of abundance in each year, and the difference between the start and end was defined as the spawning period. The peak was defined as the mode of the histogram of monthly changes in the total index of abundance in each year. See also Fig. S1, which presents the raw histograms 

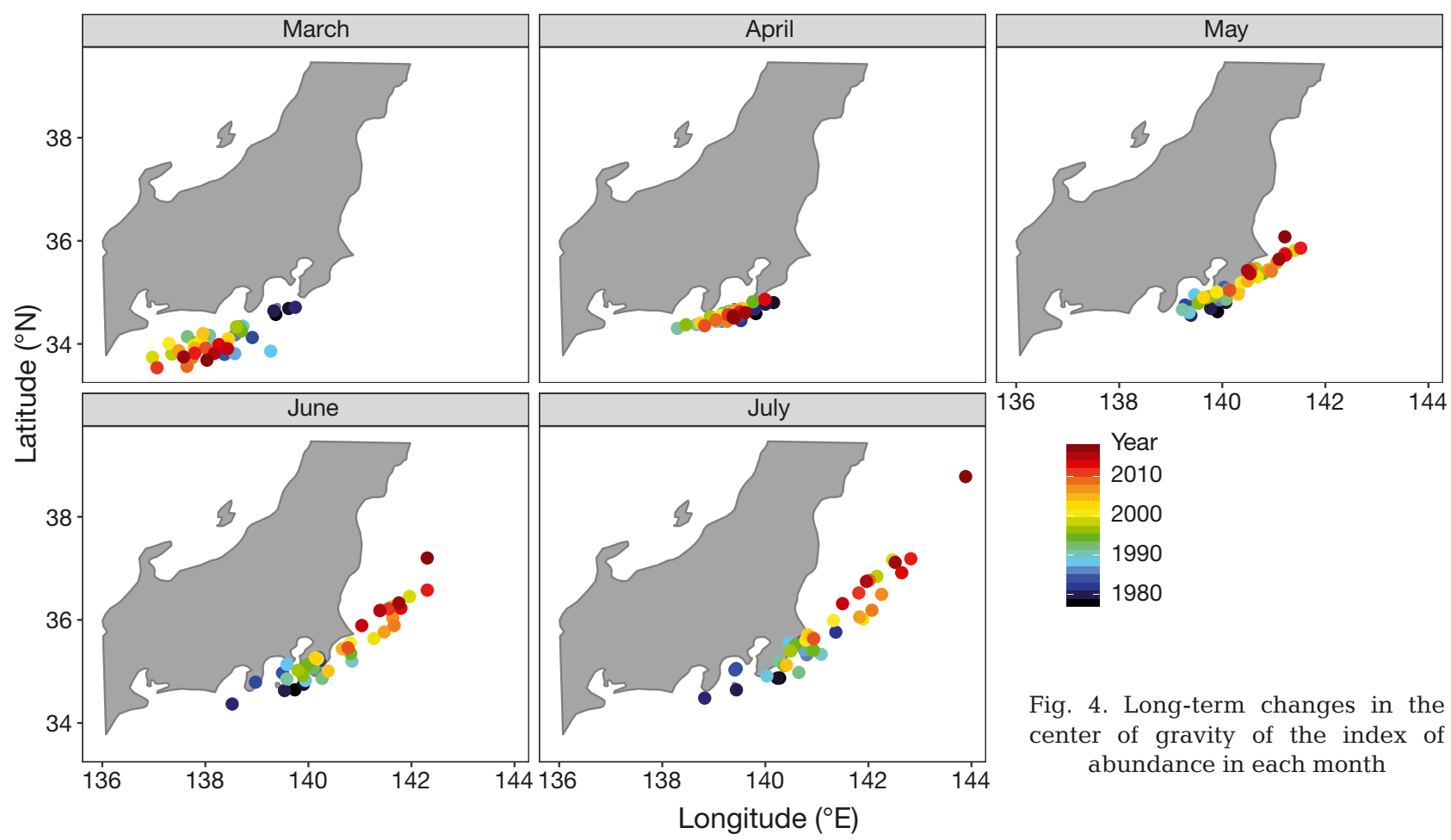

ing patterns were used (i.e. $10^{\text {th }}$ percentile for the start, $90^{\text {th }}$ percentile for the end, and $T(t)$ for the peak).

The directions of changes in the COG differed by month (Fig. 4). In March, the COG was around the Izu Islands (see Fig. 1) in the 1980s and then moved westward. In April, the COG tended to remain around the Izu Islands over the $40 \mathrm{yr}$ period. The COG from May to July changed drastically. In May, the COG moved markedly northward after the 2000s, reaching around $141^{\circ} \mathrm{E}$ and $35^{\circ} \mathrm{N}$ (Fig. 4). In June and July, the COG moved further northward, reaching around $141^{\circ} \mathrm{E}$ and $37^{\circ} \mathrm{N}$ (Fig. 4). In July of 2017 , the COG exhibited the greatest shift northward in over $40 \mathrm{yr}$, ca. $144^{\circ} \mathrm{E}$ and $39^{\circ} \mathrm{N}$.

Similar results were obtained using the data sets including only chub mackerel and both chub mackerel and spotted mackerel after 2005 (Figs. S2-S5). Although the index of abundance in March tended to be large when the data set included spotted mackerel (Figs. S2-S3), temporal patterns were very similar for the 2 data sets. Spawning patterns were also similar, but statistical analysis indicated a slight difference (Fig. S4). Although the COG in March was slightly different, spatial patterns after April were similar, and the COG after May moved markedly northward according to both data sets (Fig. S5).

\subsection{Effect of SST on changes in the distribution of reproduction}

In almost all months, the long-term changes in the COG were not random and were related to changes in the SST. In March, the probability that the slope of observed data was larger than the slope obtained from randomized data was 0.165 , indicating that the null hypothesis could not be rejected. In contrast, from April to July, the probabilities that the slope of observed data was larger than the slope obtained from randomized data were significantly lower $(\mathrm{p}<$ 0.05 in April; $\mathrm{p}<0.01$ in May; $\mathrm{p}<0.01$ in June; and $\mathrm{p}<0.01$ in July), and the null hypothesis was rejected.

In both cases in which the previous COG was set to location 4 or location 5, the location with the lowest KL distance gradually moved northward from April to July (Fig. 5) and largely corresponded with the present COG (Fig. 4). In April, the lowest KL distances were in locations 5 and 6 when the previous COG was set to locations 4 and 5, respectively. In May, the lowest KL distances were in locations 7 and 8 when the previous COG was set to locations 4 and 5, respectively. In June, the lowest KL distance was in location 9 when the previous COG was set to location 4 and 5 . In July, the lowest KL distance was in location 10 when the previous COG was set to location 4 and 5. In all cases, present SSTs of the location with the lowest 


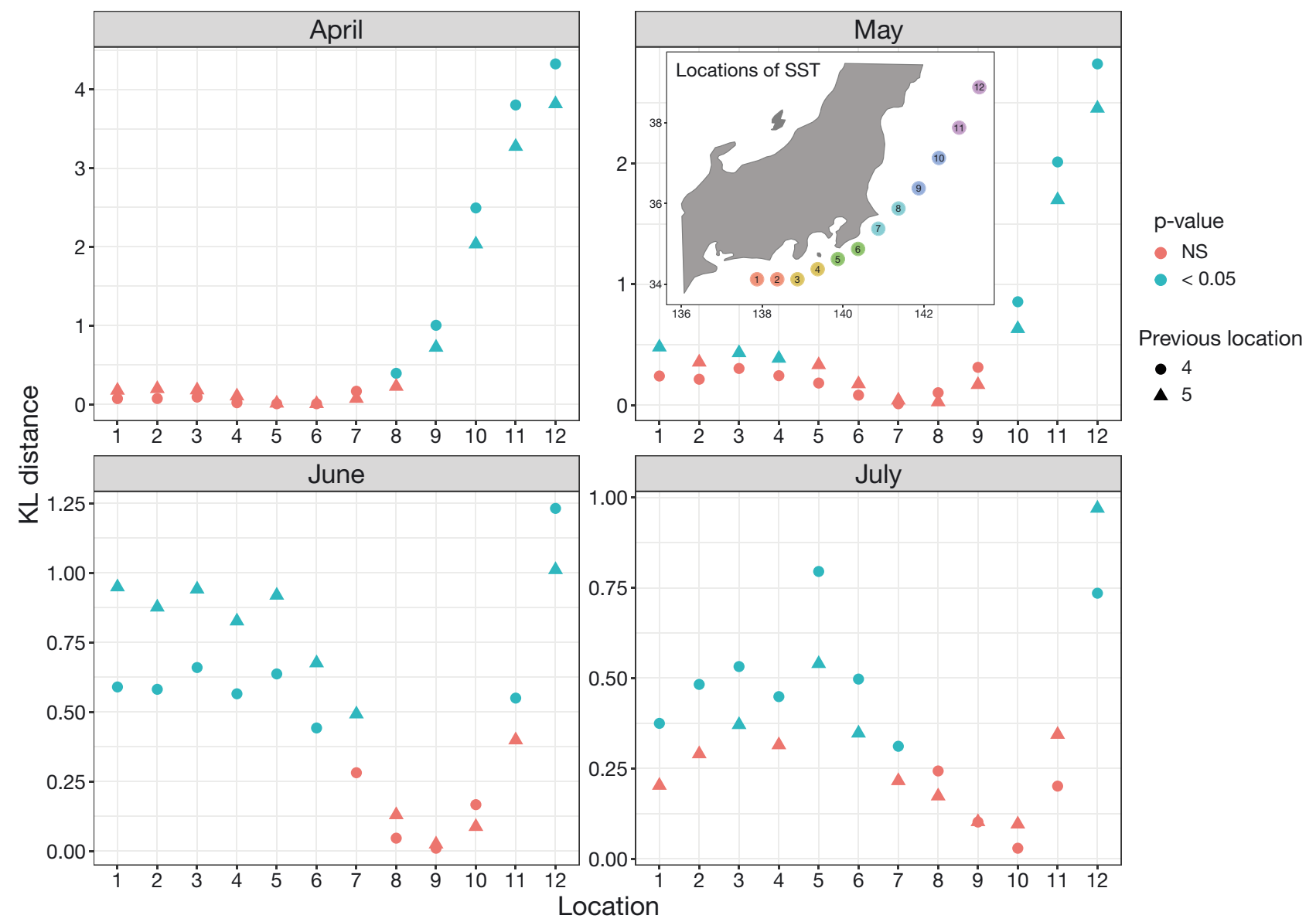

Fig. 5. Dissimilarity between SST at the COG post-2000 and SST at the COG pre-2000 in each month. Dissimilarity was calculated by Kullback-Leibler distance. Numbers on the $x$-axis correspond to the locations shown in the inset map. See Fig. S6 for more details

KL were not significantly different from previous SSTs around the Izu Islands (i.e. locations 4 and 5).

\section{DISCUSSION}

\subsection{Long-term changes in spawning pattern and spawning ground}

The start of spawning did not advance, but the spawning period was extended by a delay in the end of spawning (Fig. 3). In addition, the geographic location of the spawning ground (i.e. COG) from May to July moved northward after the 2000s (Fig. 4). These results suggest that the spawning ground of chub mackerel in the western North Pacific has changed without an advance in the spawning time, which supports the second of 4 possible scenarios we listed in the Introduction (i.e. an increase in SST changes the spawning location but not the timing). Previous meta- analyses have indicated that while phenological timing has advanced in response to increasing temperatures in the habitats of various terrestrial and marine taxa, there is substantial variation in the direction and magnitude of this phenological advance within habitats, taxa, and populations (e.g. Thackeray et al. 2008, Asch 2015). Although various hypotheses have been proposed to explain the substantial variation, species exhibit multiple responses to changing environments, including changes in distributions (Thackeray et al. 2010) and the timing of seasonal transitions. In particular, spring warming may be highly variable (Thomas et al. 2017). These hypotheses have not been evaluated owing to the lack of sufficient data to conclusively determine whether distributions, phenology, or both are changing (Henderson et al. 2017). Thus, our observation of a phenological shift with a change in distribution provides valuable evidence that distributional shifts have an impact on the direction and magnitude of phenological shifts. 
The spawning cycle of fish is generally regulated by both the physical environment, such as the sea temperature (e.g. Cardinale \& Modin 1999, Buckley et al. 2000, Shimizu 2006), and population structure, such as age/size structure (e.g. Hutchings \& Myers 1994, Marteinsdottir \& Björnsson 1999, Marteinsdottir \& Begg 2002, Watanabe 2010). The delay in the end of spawning (Fig. 3) could also result from both long-term changes in the SST through a northward shift of the spawning ground and changes in age structure. In the physical environment, the SST of the recent COG was similar to the SST of the previous COG (Fig. 5); accordingly, chub mackerel can spawn later in the spawning season. With respect to population structure, the spawning times of young adults and small adults are later than those of older adults in chub mackerel (Watanabe 2010). Indeed, the proportion of young adult chub mackerel in the western North Pacific increased and the mean age of parental fish decreased significantly over 40 yr (Fig. S23).

Behavioral changes related to spatial distribution, such as changes in migration, as well as demographic changes, are important for understanding population dynamics (Elliott 2002). While the spawning ground stayed near the Izu Islands until June in the 1990s, it has recently started to move northward in May as a result of an increasing SST (Fig. 5). This implies that chub mackerel determine the timing of their northward migration in response to the SST, and the timing of migration has advanced due to the increasing SST. Cleland et al. (2012) reported a negative relationship between phenological shifts due to climate change and reproductive performance; species that phenologically track climate (i.e. species that advance phenological timing with increasing temperatures) exhibit increased reproductive performance, whereas species that do not phenologically track climate exhibit decreased reproductive performance. The change in reproductive migration in chub mackerel in the western North Pacific may contribute to changes in population size, and therefore, considering information on the fishing season and ground with respect to the phenological shift due to climate change is useful for fisheries management.

\subsection{Utility of the VAST model}

It is important to consider the effects of changes in the survey site on the results owing to frequent alterations in survey design during long-term studies (Magurran et al. 2010). The results for long-term changes in the COG, which were estimated by applying Eq. (5) to raw data, indicated that the COG from raw data was located more westward (Fig. S24) compared with the COG from the VAST model (Fig. 4) pre-2000. This can potentially be explained by temporal changes in the survey design. Indeed, the survey area in this study changed over the $40 \mathrm{yr}$ period; the survey was not conducted north of $143^{\circ} \mathrm{E}$ and $37^{\circ} \mathrm{N}$ pre-2000, and the area gradually extended in the northeast direction (Fig. S1). Therefore, the VAST model was able to account for changes in sampling effort and design.

\subsection{Future directions}

Long-term changes in SST, which contributed to the northward shift in the spawning ground of chub mackerel, were greater in the north (Fig. S6, Table S1). This result suggests that the spawning ground of chub mackerel will move northward with increasing speed and/or the spawning period will be extended because of the suitability of the physical environment. In such an event, a delay in migration from the feeding ground or a reduction in the duration of growth of juveniles would be a cause for concern. Changes in the timing of migration and in the spatial distribution may also lead to variation in species interactions and to trophic mismatch. Therefore, to detect and evaluate these secondary effects of phenological shifts associated with climate change, spatio-temporal analyses focusing on multiple species are needed.

Our results provide evidence for a delay in the peak of egg spawning (9 d decade ${ }^{-1}$, which was calculated from the regression described in Section 3.1; Fig. 3). In contrast, a previous meta-analysis including the same species indicated an advance in the time (6.4 d decade ${ }^{-1}$ ) at which larvae of small pelagic fishes are most abundant (Asch 2015). These conflicting results can be explained by species differences in the ability to avoid inappropriate seasons for reproduction by migration. In the present study, chub mackerel adults and offspring migrate from the southwest to northeast by the Kuroshio Current (e.g. Watanabe 1970, Watanabe \& Nishida 2002; Fig. 1). In contrast, although small pelagic fishes in a previous study also migrated from south to north in the spawning season, the migration was related to the oceanic season; the northern limit of migration corresponded to the northern boundary of the seasonal upwelling (Ware \& McFarlane 1989). Hence, the small pelagic fishes could not change their spawning ground but changed the timing of spawning. Therefore, in small 
pelagic fishes, phenological and distributional shifts in reproduction associated with climate change differ among marine ecosystems, suggesting that focusing on species-specific traits and environmental properties is important for elucidating and predicting phenological shifts.

\subsection{Conclusions}

The present study revealed that the start of chub mackerel spawning did not advance, but the spawning period was extended as a result of a delay in the end of spawning in the western North Pacific. The geographic location of the spawning ground (i.e. the COG) moved northward after the 2000s, and this may be attributable to the change in SST. In addition, the SST in the COG after the 2000s was not significantly different from the SST in the previous spawning ground. Therefore, the environmental change associated with climate change would simultaneously influence phenological and distributional shifts in reproduction, suggesting the importance of considering spatio-temporal changes in reproduction.

Acknowledgements. We are grateful to Dr. M. Ichinokawa for her valuable comments and discussion, to Dr. T. Akita and Dr. M. Kai for statistical support, to Dr. M. Okazaki for data collection of SST, and to 3 anonymous reviewers and the handling editor for helpful comments on the draft. This research was financially supported by grants from the Japan Society for the Promotion of Science (JSPS) (nos. 26252031, 17H07413, and 19K15905).

\section{LITERATURE CITED}

Asch RG (2015) Climate change and decadal shifts in the phenology of larval fishes in the California Current ecosystem. Proc Natl Acad Sci USA 112:E4065-E4074

* Beaugrand G, Kirby RR (2018) How do marine pelagic species respond to climate change? Theories and observations. Annu Rev Mar Sci 10:169-197

Buckley LJ, Bradley TM, Allen-Guilmette J (2000) Production, quality, and low temperature incubation of eggs of Atlantic cod Gadus morhua and haddock Melanogrammus aeglefinus in captivity. J World Aquacult Soc 31: 22-29

Burnham KP, Anderson DR (2001) Kullback-Leibler information as a basis for strong inference in ecological studies. Wildl Res 28:111-119

Cardinale M, Modin J (1999) Changes in size-at-maturity of Baltic cod (Gadus morhua) during a period of large variations in stock size and environmental conditions. Fish Res 41:285-295

* Cherry SG, Derocher AE, Thiemann GW, Lunn N (2013) Migration phenology and seasonal fidelity of an Arctic marine predator in relation to sea ice dynamics. J Anim Ecol 82:912-921
Cleland EE, Chuine I, Menzel A, Mooney HA, Schwartz MD (2007) Shifting plant phenology in response to global change. Trends Ecol Evol 22:357-365

Cleland EE, Allen JM, Crimmins TM, Dunne JA and others (2012) Phenological tracking enables positive species responses to climate change. Ecology 93:1765-1771

* Colebrook JM (1979) Continuous plankton records: seasonal cycles of phytoplankton and copepods in the North Atlantic Ocean and the North Sea. Mar Biol 51:23-32

Colebrook JM, Robinson GA (1965) Continuous plankton records: seasonal cycles of phytoplankton and copepods in the north-eastern Atlantic and the North Sea. Bull Mar Ecol 6:123-139

Doney SC, Ruckelshaus MR, Duffy JE, Barry JP and others (2012) Climate change impacts on marine ecosystems. Annu Rev Mar Sci 4:11-37

* Edwards M, Richardson A (2004) Impacts of climate change on marine pelagic phenology and trophic mismatch. Nature 430:881-884

Elliott JM (2002) A quantitative study of day-night changes in the spatial distribution of insects in a stony stream. J Anim Ecol 71:112-122

FAO (2018) The state of world fisheries and aquaculture 2018 - meeting the sustainable development goals. FAO, Rome

Fréon P, Cury P, Shannon L, Roy C (2005) Sustainable exploitation of small pelagic fish stocks challenged by environmental and ecosystem changes: a revue. Bull Mar Sci 76:385-462

Greve W, Prinage S, Zidowitz H, Nast J, Reiners F (2005) On the phenology of North Sea ichthyoplankton. ICES J Mar Sci 62:1216-1223

*Henderson ME, Mills KE, Thomas AC (2017) Effects of spring onset and summer duration on fish species distribution and biomass along the Northeast United States continental shelf. Rev Fish Biol Fish 27:411-424

* Hovel RA, Carlson SM, Quinn TP (2017) Climate change alters the reproductive phenology and investment of a lacustrine fish, the three-spine stickleback. Glob Change Biol 23:2308-2320

* Hutchings JA, Myers RA (1994) What can be learned from the collapse of a renewable resource? Atlantic cod, Gadus morhua, of Newfoundland and Labrador. Can J Fish Aquat Sci 51:2126-2146

Ko HL, Wang YT, Chiu TS, Lee MA and others (2013) Evaluating the accuracy of morphological identification of larval fishes by applying DNA barcoding. PLOS ONE 8: e53451

Kullback S, Leibler RA (1951) On information and sufficiency. Ann Math Stat 22:79-86

Lindgren F (2012) Continuous domain spatial models in R-INLA. ISBA Bull 19:14-20

* Magurran AE, Baillie SR, Buckland ST, Dic JM and others (2010) Long-term datasets in biodiversity research and monitoring: assessing change in ecological communities through time. Trends Ecol Evol 25:574-582

Marteinsdottir G, Begg GA (2002) Essential relationships incorporating the influence of age, size and condition on variables required for the estimation of reproductive potential in Atlantic cod Gadus morhua. Mar Ecol Prog Ser 235:235-256

Marteinsdottir G, Björnsson H (1999) Time and duration of spawning cod in Icelandic waters. ICES CM 1999/Y:34. International Council for the Exploration of the Sea, Copenhagen 
Oozeki Y, Takasuka A, Kubota H, Barange M (2007) Characterizing spawning habitats of Japanese sardine (Sardinops melanostictus), Japanese anchovy (Engraulis japonicus), and Pacific round herring (Etrumeus teres) in the northwestern Pacific. Calif Coop Ocean Fish Invest Rep 48:191-203

Parmesan C, Yohe G (2003) A globally coherent fingerprint of climate change impacts across natural systems. Nature 421:37-42

R Development Core Team (2018) R: a language and environment for statistical computing. R Foundation for Statistical Computing, Vienna

Root TL, Price JT, Hall KR, Schneider SH, Rosenzweig C, Pounds JA (2003) Fingerprints of global warming on wild animals and plants. Nature 421:57-60

Shimizu A (2006) Environmental regulations of reproductive cycles in teleosts. Bull Fish Res Agency Jpn 4:1-12

Sims DW, Genner MJ, Southward AJ, Hawkins SJ (2001) Timing of squid migration reflects North Atlantic climate variability. Proc R Soc B 268:2607-2611

Sims DW, Wearmouth VJ, Genner MJ, Southward AJ, Hawkins SJ (2004) Low-temperature-driven early spawning migration of a temperate marine fish. J Anim Ecol 73: 333-341

Takasuka A, Oozeki Y, Kubota H (2008a) Multi-species regime shifts reflected in spawning temperature optima of small pelagic fish in the western North Pacific. Mar Ecol Prog Ser 360:211-217

Takasuka A, Kubota H, Oozeki Y (2008b) Spawning overlap of anchovy and sardine in the western North Pacific. Mar Ecol Prog Ser 366:231-244

Takasuka A, Tadokoro K, Okazaki Y, Ichikawa T, Sugisaki H, Kuroda H, Oozeki Y (2017) In situ filtering rate variability in egg and larval surveys off the Pacific coast of Japan: Do plankton nets clog or over-filter in the sea? Deep-Sea Res I 120:132-137

Takasuka A, Yoneda M, Oozeki Y (2019) Density dependence in total egg production per spawner for marine fish. Fish Fish 20:125-137

Thackeray SJ, Jones ID, Maberly SC (2008) Long-term change in the phenology of spring phytoplankton: species-specific responses to nutrient enrichment and climate change. J Ecol 96:523-535

Thomas AC, Pershing AJ, Friedland KD, Nye JA and others (2017) Seasonal trends and phenology shifts in sea surface temperature on the North American northeastern continental shelf. Elementa Sci Anthropocene 5:48-64

Thorson JT (2019) Guidance for decisions using the Vector Autoregressive Spatio-Temporal (VAST) package in stock, ecosystem, habitat and climate assessments. Fish Res 210:143-161

Thorson JT, Kristensen K (2016) Implementing a generic method for bias correction in statistical models using random effects, with spatial and population dynamics examples. Fish Res 175: 66-74

Editorial responsibility: Alistair Hobday, Hobart, Tasmania, Australia
Thorson JT, Barnett LAK (2017) Comparing estimates of abundance trends and distribution shifts using singleand multispecies models of fishes and biogenic habitat. ICES J Mar Sci 74:1311-1321

* Thorson JT, Shelton AO, Ward EJ, Skaug HJ (2015) Geostatistical delta-generalized linear mixed models improve precision for estimated abundance indices for West Coast groundfishes. ICES J Mar Sci 72:1297-1310

Thorson JT, Pinsky ML, Ward EJ (2016) Model-based inference for estimating shifts in species distribution, area occupied and centre of gravity. Methods Ecol Evol 7: 990-1002

Thorson JT, Ianelli JN, Kotwicki S (2017) The relative influence of temperature and size-structure on fish distribution shifts: a case-study on walleye pollock in the Bering Sea. Fish Fish 18:1073-1084

Walther GR, Post E, Convey P, Menzel A and others (2002) Ecological responses to recent climate change. Nature 416:389-395

Ware DM, McFarlane GA (1989) Fisheries production domains in the northeast Pacific Ocean. Can Spec Publ Fish Aquat Sci 108:359-379

Watanabe C (2010) Changes in the reproductive traits of the Pacific stock of chub mackerel Scomber japonicus and their effects on the population dynamics. Bull Jpn Soc Fish Oceanogr 74:46-50 (in Japanese with English abstract)

W Watanabe C, Nishida H (2002) Development of assessment techniques for pelagic fish stocks: applications of daily egg production method and pelagic trawl in the northwestern Pacific Ocean. Fish Sci 68:97-100

Watanabe C, Yatsu A (2006) Long-term changes in maturity at age of chub mackerel (Scomber japonicus) in relation to population declines in the waters off northeastern Japan. Fish Res 78:323-332

Watanabe C, Hanai T, Meguro K, Ogino R, Kubota Y, Kimura R (1999) Spawning biomass estimates of chub mackerel Scomber japonicus of Pacific subpopulation off central Japan by a daily egg production method. Bull Jpn Soc Sci Fish 65:695-702 (in Japanese with English abstract)

Watanabe T (1970) Morphology and ecology of early stages of life in Japanese common mackerel, Scomber japonicus Houttuyn, with special reference to fluctuation of population. Bull Tokai Reg Fish Res Lab 62:1-283 (in Japanese with English abstract)

*Winder M, Schindler DE (2004) Climate change uncouples trophic interactions in an aquatic ecosystem. Ecology 85: 2100-2106

Yukami R, Watanabe C, Kamimura Y, Kishida T (2017) Stock assessment and evaluation for the Pacific stock of chub mackerel (fiscal year 2016). In: Marine fisheries stock assessment and evaluation for Japanese waters (2016/ 2017). Fisheries Agency and Fisheries Research Agency of Japan, Yokohama, Kanagawa, p 154-200 (in Japanese)

Submitted: January 25, 2019; Accepted: June 14, 2019

Proofs received from author(s): August 11, 2019 